\title{
A dynamic stall model for airfoils with deformable trailing edges
}

\author{
Andersen, Peter Bjørn; Gaunaa, Mac; Bak, Dan Christian; Hansen, Morten Hartvig
}

Published in:

Journal of Physics Conference Series

Link to article, DOI:

$10.1088 / 1742-6596 / 75 / 1 / 012028$

Publication date:

2007

Document Version

Publisher's PDF, also known as Version of record

Link back to DTU Orbit

Citation (APA):

Andersen, P. B., Gaunaa, M., Bak, D. C., \& Hansen, M. H. (2007). A dynamic stall model for airfoils with deformable trailing edges. Journal of Physics Conference Series, 75, [012028]. https://doi.org/10.1088/1742$6596 / 75 / 1 / 012028$

\section{General rights}

Copyright and moral rights for the publications made accessible in the public portal are retained by the authors and/or other copyright owners and it is a condition of accessing publications that users recognise and abide by the legal requirements associated with these rights.

- Users may download and print one copy of any publication from the public portal for the purpose of private study or research.

- You may not further distribute the material or use it for any profit-making activity or commercial gain

- You may freely distribute the URL identifying the publication in the public portal

If you believe that this document breaches copyright please contact us providing details, and we will remove access to the work immediately and investigate your claim 
A Dynamic Stall Model for Airfoils with Deformable Trailing Edges

This content has been downloaded from IOPscience. Please scroll down to see the full text. 2007 J. Phys.: Conf. Ser. 75012028

(http://iopscience.iop.org/1742-6596/75/1/012028)

View the table of contents for this issue, or go to the journal homepage for more

Download details:

IP Address: 192.38.90.17

This content was downloaded on 09/06/2016 at 09:54

Please note that terms and conditions apply. 


\title{
A Dynamic Stall Model for Airfoils with Deformable Trailing Edges
}

\author{
Peter Bjørn Andersen ${ }^{1}$, Mac Gaunaa ${ }^{2}$, Christian Bak ${ }^{2}$, Morten Hartvig Hansen ${ }^{2}$ \\ ${ }^{1}$ Ph.D student, Risø National Laboratory-DTU, Roskilde, DK-4000, Denmark \\ ${ }^{2}$ Senior Scientist, Risø National Laboratory-DTU, Roskilde, DK-4000, Denmark \\ peter.bjoern.andersen@risoe.dk
}

\begin{abstract}
The present work contains an extension of the Beddoes-Leishman (B-L) type dynamic stall model, as described by Hansen et al. [7]. In this work a Deformable Trailing Edge Geometry (DTEG) has been added to the dynamic stall model. The model predicts the unsteady aerodynamic forces and moments on an airfoil section undergoing arbitrary motion in heave, lead-lag, pitch, Trailing Edge (TE) flapping. In the linear region, the model reduces to the inviscid model of Gaunaa [4], which includes the aerodynamic effect of a thin airfoil with a deformable camberline in inviscid flow. Therefore, the proposed model can be considered a crossover between the work of Gaunaa for the attached flow region and Hansen et al. The model will be compared to wind tunnel measurements from Velux described by Bak et al. [8]. Keywords: Dynamic Stall, Trailing edge flaps
\end{abstract}

\section{Notations}

AOA Angle Of Attack, Airfoil inflow angle

$\mathrm{A}_{\mathrm{i}}, \mathrm{b}_{\mathrm{i}} \quad A_{i}$ and $b_{i}$ are profile specific constants for near wake state variables

$\alpha \quad$ See AOA

$\alpha_{0, \text { st }}^{\beta} \quad$ Equivalent AOA shift in attached flow lift curve due to a static $\beta$ deflection angle

$\alpha_{0, \mathrm{dyn}}^{\beta}$ Equivalent AOA shift in attached flow lift curve due to the first $\beta$ derivative

$\alpha_{0}^{\mathrm{c}} \quad$ Equivalent AOA shift in attached flow lift curve due to a cambered profile

$\alpha_{0} \quad$ Sum of $\alpha_{0, \text { dyn }}^{\beta}, \alpha_{0, \text { st }}^{\beta}$ and $\alpha_{0}^{\mathrm{c}}$

$\alpha_{3 / 4} \quad$ Geometrical angle of attack at the threequarter point

$\alpha_{E} \quad$ Effective geometric AOA using the retarding unsteady near wake effects from the shed vortexes

$\alpha_{o, E} \quad$ Effective equivalent AOA shift with retarding unsteady near wake effects from the shed vortexes

\begin{tabular}{|c|c|}
\hline & flection angle \\
\hline & chord \\
\hline & Airfoil chord \\
\hline$C_{D}$ & Drag coefficient at zero lift \\
\hline$C_{D}^{\text {dyn }}$ & Dynamic drag coefficient \\
\hline $\mathrm{C}_{\mathrm{L}}^{\mathrm{P}}$ & The attached flow unsteady lift \\
\hline $\mathrm{C}_{\mathrm{L}}^{\mathrm{P}}$ & $\begin{array}{l}\text { Helping state variable which is the lift } \\
\text { coefficient after the pressure time-lag is } \\
\text { included }\end{array}$ \\
\hline & Stationary lift as function of $\mathrm{AOA}$ \\
\hline & $\begin{array}{l}\text { Fully separated lift (stationary) } \\
\text { function of AOA }\end{array}$ \\
\hline & Lift slope for attached flow regime \\
\hline & $\begin{array}{l}\text { Dynamic lift as function of AOA and } \\
\text { DTEG deflection angle. }\end{array}$ \\
\hline & Moment coefficient at zero lift \\
\hline & Dynamic moment coefficient \\
\hline & $\begin{array}{l}\text { Parameter following the } \\
\text { camberline. }\end{array}$ \\
\hline
\end{tabular}




\begin{tabular}{|c|c|c|c|}
\hline $\mathrm{f}^{\mathrm{dyn}}$ & $\begin{array}{l}\text { Dynamic separation point values } \\
\text { between one and zero. }\end{array}$ & $\mathrm{U}, \mathbf{U}$ & $\begin{array}{l}\text { Free-stream air velocity }\left(\mathrm{U}_{\mathrm{x}}, \mathrm{U}_{\mathrm{y}} \text { are }\right. \\
\text { coordinate components of } \mathrm{U})\end{array}$ \\
\hline $\mathrm{f}^{\mathrm{st}}$ & $\begin{array}{l}\text { Stationary separation point values } \\
\text { between one and zero. }\end{array}$ & $\begin{array}{l}\omega \\
\mathrm{W}\end{array}$ & $\begin{array}{l}\text { Frequency in radians pr. second } \\
\text { Three-quarter point downwash }\end{array}$ \\
\hline $\mathrm{H}_{\mathrm{dydx}}$ & $\begin{array}{l}\text { Deflections integrals used by DTEG } \\
\text { dynamics }\end{array}$ & $\mathrm{w}_{\beta}$ & $\begin{array}{l}\text { Three-quarter point downwash } \\
\text { contribution from DTEG }\end{array}$ \\
\hline $\mathrm{H}_{\mathrm{y}}$ & See $H_{d y d x}$ & $\mathrm{w}_{3 / 4}$ & $\begin{array}{l}\text { Three-quarter point } \\
\text { contribution from airfoil }\end{array}$ \\
\hline $\mathrm{k}$ & Reduced frequency $\mathrm{k}=\omega \mathrm{b} / \mathrm{U}$ & $\mathrm{x}, \mathrm{y}, \mathrm{z}$ & Local coordinates used to describe \\
\hline$\tau_{\mathrm{p}}, \tau_{\mathrm{b}}$ & $\begin{array}{l}\text { Dynamic pressure-lift time lag and } \\
\text { buildup/destruction time lag for the } \\
\text { boundary layer }\end{array}$ & $\mathrm{x}_{\mathrm{i}}, \mathrm{y}_{\mathrm{i}}, \mathrm{Z}_{\mathrm{i}}$ & $\begin{array}{l}\text { DTEG } \\
\text { Indicial state variables for the near } \\
\text { wake history }\end{array}$ \\
\hline
\end{tabular}

\section{Introduction}

Adding a Trailing Edge (TE) flap to a wing is a well known method for changing the aerodynamic pressure distribution around the wing, and thereby controlling the aeroelastic behavior. TE flap devices are used for noise and vibration reductions on rotorcrafts. Extensive works have been conducted in this area and the authors refer to the review paper by Friedmann [13] for more details. For the purpose of this paper the flap or the Deformable Trailing Edge Geometry (DTEG) is characterized by a smooth and continuous gradient from the non-deformable part of the airfoil to the deformable part. Furthermore, the part of the DTEG closest to the trailing edge has the largest structural rotations and at the point where the DTEG is fixed to the non-deformable part of the airfoil there is no structural rotation. This type of DTEG was chosen in Risø's previous work because flow separation and thereby corresponding noise and drag are reduced, compared to the rigid flap. Recent works have shown that the potential fatigue load reduction by use of DTEG may be greater than for traditional pitch control methods $[3,5]$. By enabling the trailing edge to move independently and quickly along the radial position of the blade, local fluctuations in the aerodynamic forces can be compensated for by deformation of the airfoil geometry. At Risø National Laboratory, a continuous research of using DTEG for reducing load fluctuations on wind turbines have been carried out [1-6]. Using a simplified aeroelastic model of a Vestas V66 wind turbine Andersen et al.[5] found that the equivalent flapwise blade root moment could be reduced $60 \%$ for inflow with $10 \%$ turbulence using 7 meter adaptive DTEG on the 33-m blade. In Figure 1 an airfoil with a DTEG is shown.

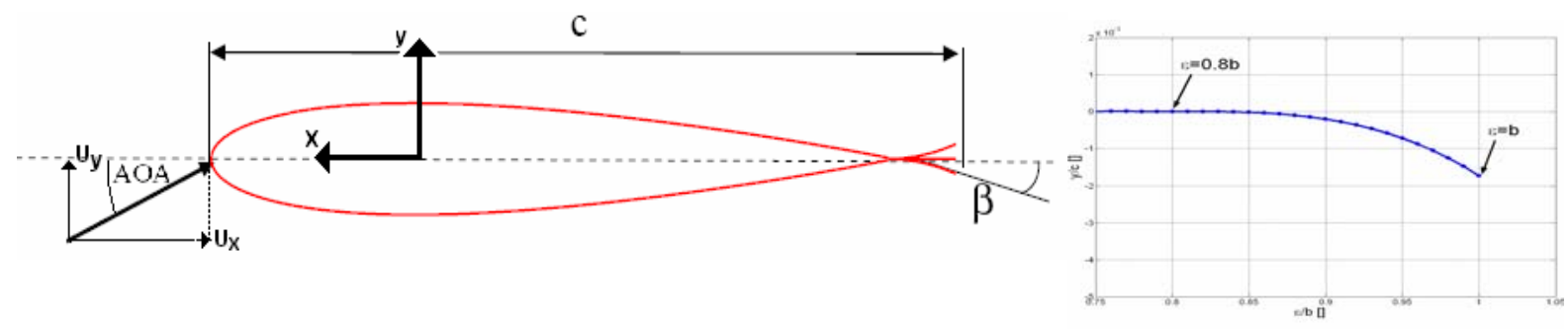

Figure 1 Left: Airfoil equipped with a DTEG.

Right: $(\varepsilon, y)$ used to model one degree DTEG deflection

All previous work investigating active load reduction using DTEG carried out at Risø National Laboratory has employed the aerodynamic model of Gaunaa [4], which is an inviscid model. Therefore, the investigations have been confined to angles of attack in the linear region, where effects of stall are not present. Due to the great load reduction potential revealed previously, further investigations closer to and somewhat into the stalled region is needed. The present work contains an extension of the Beddoes-Leishman (B-L) type dynamic stall model, as described by Hansen et al. [7] 
with the static and dynamic effect of a DTEG. The model predicts the unsteady aerodynamic forces and moments on an airfoil section undergoing arbitrary motion in heave, lead-lag, pitch and trailing edge (TE) flapping, and includes the effect of shed vorticity from the trailing edge and the effect of an instationary TE separation point. In the linear region, the model reduces to the inviscid model of Gaunaa. Therefore, the proposed model can be considered a crossover between the work of Gaunaa for the attached flow region and Hansen et al. for the separated flow region and will make the aerodynamic forces a function of angle of attack (AOA) and deflection of the flap ( $\beta$ ). The range of the TE deflection is limited to $+/-5$ degrees, the model is not expected handle large TE deflections e.g. 30-45 degrees. The model is validated against wind tunnel measurements from Velux as described by Bak et al. [8].

\section{Model}

The model consists of two parts; an inviscid and a viscous and part. In the inviscid part the airfoil is represented by its camberline with a mounted DTEG also represented by a camberline. The influence from the shed vorticity in the wake is described by a series of time-lags as used by Hansen et al.[7] and Gaunaa [4], in which the time-lag is approximated using an indicial function first outlined by Von Karman et al [9], making the practical calculation of the aerodynamic response numerically very efficient by use of Duhamel superposition. In the viscous part of the model the dynamic behavior of the trailing edge (TE) separation is likewise modeled using an assumed time-lag between pressure distribution and lift and a time-lag for the separation point in the dynamic boundary layer. Using the same conditions as specified by Hansen et al. [7], the TE separation is considered under stalled conditions.

Based on the work of Gaunaa, the lift, drag and moment can be found for an airfoil using a series of modeshapes which model an unsteady camberline. A single modeshape, illustrated in Figure 1, is implemented in the model to represent the DTEG undergoing unsteady deformations. Actuating the DTEG causes a change in the equivalent three-quarter downwash $\left(w_{\beta}\right)$. It should be noted that $w_{\beta}$ is not a physical property but should be regarded as a useful numerical number for determining the effect of TE shed vortices. For steady conditions using a single deformation modeshape to model the DTEG, $w_{\beta}$ is given by

$$
\frac{w_{\beta}}{\bar{U}}=-\frac{H_{d y d \varepsilon}}{2 \pi} \beta-\frac{H_{y}}{2 \pi \bar{U}} \frac{\partial \beta}{\partial t}
$$

where $\mathrm{U}$ is the relative wind velocity the profile experiences and $\beta$ is the deflection of the DTEG. The deflection integrals $\mathrm{H}_{\mathrm{y}}$ and $\mathrm{H}_{\mathrm{dyd} \varepsilon}$ are given by (2) and (3). Please note that the lower bound of 0.8 used in the integrals marks the start of a DTEG with a chordwise length of $10 \%$ using the chordwise notation suggested by Theodorsen of $x=0$ for $c / 2$ and $x=-c / 2=-b$ for the TE and $x=c / 2=b$ for the LE.

$$
\begin{aligned}
& H_{y}=-2 \int_{0.8}^{1} \frac{y(x) \sqrt{1-x^{2}}}{x-1} d x \\
& H_{d y d \varepsilon}=-2 \int_{0.8}^{1} \frac{\frac{\partial y}{\partial \varepsilon}(\varepsilon(x)) \sqrt{1-x^{2}}}{x-1} d x
\end{aligned}
$$

In some cases, empirical data for the DTEG is known e.g. from wind tunnel measurements. It is possible to introduce the empirical term $\triangle C_{L, D T E G}{ }^{s t}$, which is the lift contribution from the DTEG by replacing the theoretical $H_{d y d x}$. The downwash can be represented by an AOA representation given by 


$$
\begin{aligned}
& \alpha_{0, s t}^{\beta}=\frac{H_{d y d x}}{2 \pi} \beta \cong \frac{\Delta C_{L, D T E G}\left(\alpha_{0}^{c}, \beta\right)}{C_{L, \alpha}} \\
& \alpha_{0, d y n}^{\beta}=\frac{H_{y}}{2 \pi \bar{U}} \frac{\partial \beta}{\partial t}
\end{aligned}
$$

where the term $C_{L, \alpha}$ marks the attached lift slope at zero DTEG deflection $\beta$. The term $\alpha_{0, s t}{ }^{\beta}$ is an equivalent $\mathrm{AOA}$ shift in attached flow lift curve due to a static $\beta$ deflection angle and $\alpha_{0, d y n}{ }^{\beta}$ marks the contribution from the first $\beta$ derivative to $w_{\beta}$ given by Equation (1). Using Equation (4) the overall lift offset represented by a shift in AOA $\left(\alpha_{0}\right)$ due to a chambered profile and the use of a DTEG becomes

$$
\alpha_{o}=\alpha_{0, s t}^{\beta}+\alpha_{0, d y n}^{\beta}+\alpha_{0}^{c}
$$

where the term $\alpha_{0}{ }^{c}$ is the offset at zero lift due to a standard cambered profile.

The three-quarter point downwash without the influence of a DTEG is given by the variable $w_{3 / 4}$. The effective geometric AOA $\left(\alpha_{E}\right)$ is found using the unsteady wake effects from the shed vortices as previously described using the Duhamel integral formulation. The profile has an unsteady camberline due to the added DTEG, which causes $\alpha_{0}$ to be instationary. The unsteady offset of AOA $\alpha_{0}$ is called $\alpha_{0, E}$. The geometrical angle of attack at the three-quarter point is marked $\alpha_{3 / 4}$. The unsteady DTEG deflection angle $\left(\beta_{E}\right)$ is based on the static DTEG deflection angle $(\beta)$ using the same integral formulation.

$$
\left[\begin{array}{c}
\alpha_{E} \\
\alpha_{0, E} \\
\beta_{E}
\end{array}\right]=\left[\begin{array}{c}
\alpha_{3 / 4} \\
\alpha_{0} \\
\beta
\end{array}\right]\left(1-\sum_{i} A_{i}\right)+\sum_{i}\left[\begin{array}{c}
x_{i} \\
y_{i} \\
z_{i}
\end{array}\right]
$$

where the indicial state variables for the wake history is given by

$$
\begin{aligned}
& x_{i}=x_{i} \cdot e^{-d s \cdot b_{i}}+A_{i} \alpha_{3 / 4}\left(1-e^{-d s \cdot b_{i}}\right) \\
& y_{i}=y_{i} \cdot e^{-d s \cdot b_{i}}+A_{i} \alpha_{0}\left(1-e^{-d s \cdot b_{i}}\right) \\
& z_{i}=z_{i} \cdot e^{-d s \cdot b_{i}}+A_{i} \beta\left(1-e^{-d s \cdot b_{i}}\right)
\end{aligned}
$$

where $d s$ is an integrated time constant with respect to half a chord length and $A_{i}$ and $b_{i}$ are profile specific constants suggested by Jones [11]. The static flat plate lift in a Kirchoff flow [10] with the DTEG $(\beta)$ deflection angle is written as

$$
C_{L}^{s t}(\alpha)+\Delta C_{L, D T E G}^{s t}(\alpha, \beta)=C_{L, \alpha}\left(\frac{1+\sqrt{f^{s t}(\alpha, \beta)}}{2}\right)^{2}\left[\alpha-\alpha_{0}(\beta)\right]
$$

where $\alpha_{0}$ contains the static AOA offset for a cambered profile plus the DTEG deflection contribution to the AOA offset. The steady separation point $\left(f^{s t}\right)$ is determined by inversion of Equation (8) 


$$
\begin{aligned}
f^{s t} & =\left(2 \sqrt{\frac{C_{L}^{s t}(\alpha)+\Delta C_{L, D T E G}^{s t}(\alpha, \beta)}{C_{L, \alpha}\left(\alpha-\alpha_{0}(\beta)\right)}}-1\right)^{2} \\
C_{L, \alpha} & =\max \left\{\frac{C_{L}^{s t}(\alpha)}{\alpha-\alpha_{0}(\beta=0)}\right\}
\end{aligned}
$$

where $C_{L, \alpha}$ is the slope of the linear region of attached flow at zero $\beta$. It is assumed that the lift in the attached region follows the $C_{L, \alpha}$ slope. The lift coefficient for fully separated flow $\left(C_{L}{ }^{f_{s}}\right)$ is given by Equation (12). For fully attached flow $\left(f^{t}=1\right)$ Equation (11) is inserted into (12) to avoid dividing by zero.

$$
\begin{array}{ll}
C_{L}^{s t}=C_{L, \alpha}\left(\alpha-\alpha_{0}\right) f^{s t}+C_{L}^{f s}\left(1-f^{s t}\right) & \\
C_{L}^{f s}=\frac{C_{L}^{s t}(\alpha)+\Delta C_{L, D T E G}^{s t}(\alpha, \beta)-C_{L, \alpha}\left(\alpha-\alpha_{0}\right) f^{s t}}{1-f^{s t}} & , \text { for } f^{s t} \neq 1 \\
C_{L}^{f s}=\frac{C_{L}^{s t}(\alpha, \beta)}{2} & , \text { for } f^{s t}=1
\end{array}
$$

Figure 2 illustrates the static lift for fully separated and attached flow along with the steady separation point for various DTEG deflections and AOA.

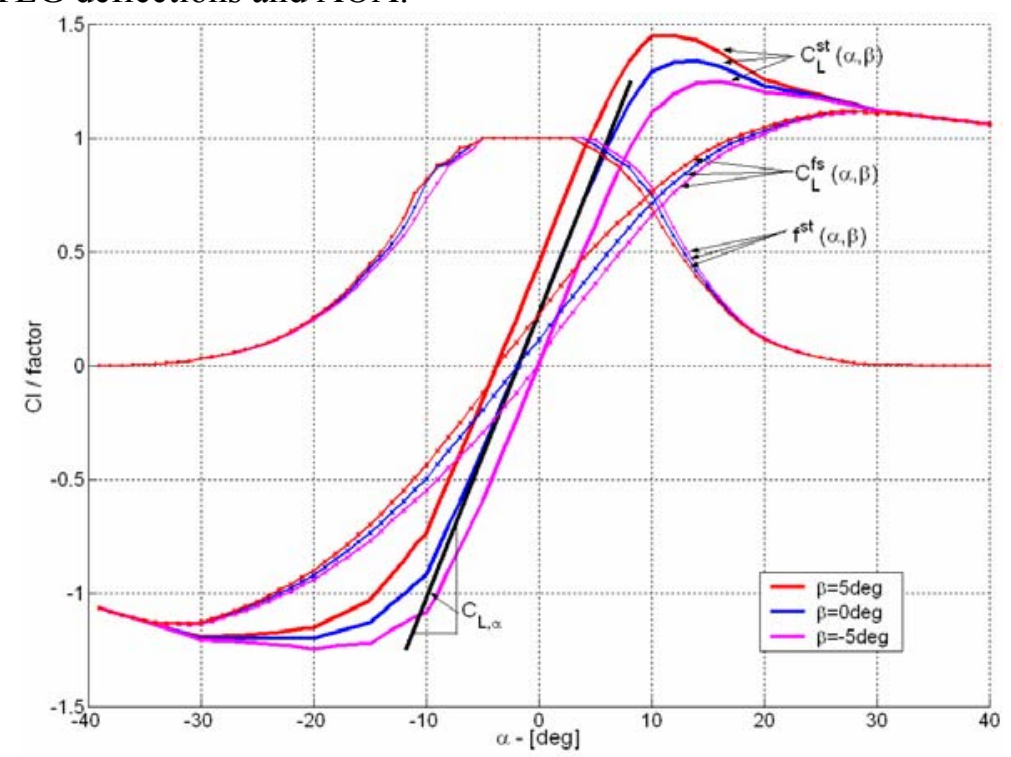

Figure $2 C_{L}^{s t}, C_{L}^{f_{s}}$ and $f^{s t}$ for DTEG deflection of $\beta=-5^{0}, 0^{0}, 5^{0}$ at AOA from $+/-40^{0}$.

The unsteady lift for attached flow is rewritten to include the DTEG deflection given by the unsteady offset of AOA in Equation (14). Higher order terms of heave motion and flow rate given by the unsteady version of Theodorsen's [12] theory have been neglected. Two state variables in the B-L model are used to describe the dynamic behaviour of the TE separation. The separation is related to the pressure distribution over the airfoil, and the pressure is related to the lift on the airfoil; for a given lift there is a certain pressure distribution with a certain separation point. It is assumed that there is a 
time-lag between the pressure and lift modelled as Equation (15) and the dynamics of the boundary layer is modelled as Equation (16).

$$
\begin{aligned}
& C_{L}^{P}=C_{L, \alpha}\left(\alpha_{E}-\alpha_{0, E}\right)+\pi b \frac{\dot{\alpha}}{\bar{U}}, \\
& C_{L}^{p '}=C_{L}^{p} \cdot e^{\frac{-d s}{\tau_{p}}}+C_{L}^{P}\left(1-e^{\frac{-d s}{\tau_{p}}}\right) \quad, \quad \beta_{E}^{\prime}=\beta_{E}^{\prime} \cdot e^{\frac{-d s}{\tau_{p}}}+\beta_{E}\left(1-e^{\frac{-d s}{\tau_{p}}}\right) \\
& f^{d y n}=f^{d y n} e^{\frac{-d s}{\tau_{b}}}+f^{s t}\left(1-e^{\frac{-d s}{\tau_{b}}}\right) \\
& f^{s t}{ }^{\prime}=f^{s t}(\alpha, \beta) \text {, where } \alpha=\frac{C_{L}^{p '}}{C_{L, \alpha}}, \beta=\beta_{E}{ }^{\prime}
\end{aligned}
$$

The time constants $\tau_{\mathrm{p}}$ and $\tau_{\mathrm{b}}$ marks the time-lags for the dynamic pressure-lift lag and the dynamics in the build-up/destruction lag of the boundary layer. The $C_{L}{ }^{P}$, is a helping state variable containing the equivalent lift coefficient after the pressure time-lag has been included and $\beta_{E}{ }^{\prime}$ is the effective pressure lagged DTEG deflection angle. Using this semi-dynamic lift coefficient $C_{L}{ }^{P}$, and effective DTEG deflection angle $\beta_{E}$ the pressure lagged separation point $f^{t}$, is found using Equation (9). The dynamic separation point is used in the linear interpolation between the full separation lift and the attached flow lift to find the overall dynamic lift with TE separation.

$$
C_{L}^{d y n}=C_{L, \alpha}\left(\alpha_{E}-\alpha_{0, E}\right) f^{d y n}+C_{L}^{f s}\left(1-f^{d y n}\right)+\pi b \frac{\dot{\alpha}}{\bar{U}}
$$

The dynamic drag is operating around a static drag curve provided as input to the model. The drag consists of three parts; Induced drag, viscous drag and DTEG contribution to drag modelled as a change in AOA offset similar to the dynamic lift. A description of the induced drag is provided by Hansen et al. [7]. The viscous drag is either calculated using CFD or measured in a wind tunnel. The DTEG contribution to the geometric and effective AOA is included using the DTEG specific helping variables

$$
\begin{aligned}
& \alpha_{3 / 4, D T E G}=\alpha_{3 / 4}-\left(\alpha_{0, s t}^{\beta}+\alpha_{0, d y n}^{\beta}\right) f^{d y n} \\
& \alpha_{E, D T E G}=\alpha_{E}-\left(\alpha_{0, E}-\alpha_{0}^{c}\right) f^{d y n}
\end{aligned}
$$

where the term $\alpha_{3 / 4, D T E G}$ contains the steady AOA offset to the $C_{L}$ curve with the effect of the DTEG contribution to the AOA offset and $\alpha_{E, D T E G}$ contains the unsteady AOA offset. The static camber AOA offset $\alpha_{0}{ }^{c}$ is removed from $\alpha_{o, E}$ because it is part of both $\alpha_{o, E}$ and $\alpha_{E}$. The suggested model assumes that the DTEG drag contribution scales with the dynamic separation point function $\left(f^{d y n}\right)$. This assumption is not fully validated, but considered valid for the two extreme cases (fully attached flow and fully separated flow). The original dynamic drag $C_{D}{ }^{d y n}$ equation by Hansen et al. [7] is otherwise reused. It is assumed that the drag coefficient at zero lift $\left(C_{D, 0}\right)$ is unaffected by the DTEG. 


$$
\begin{aligned}
& C_{D}^{d y n}=C_{D}^{s t}\left(\alpha_{E, D T E G}\right)+\Delta C_{D}^{i n d}+\Delta C_{D}^{f^{d y n}} \\
& \Delta C_{D}^{\text {ind }}=\left(\alpha_{3 / 4, D T E G}-\alpha_{E, D T E G}\right) C_{L}^{d y n} \\
& \Delta C_{D}^{f^{d y n}}=\left(C_{D}^{s t}\left(\alpha_{E, D T E G}\right)-C_{D, 0}\right)\left(\left(\frac{1-\sqrt{f^{d y n}}}{2}\right)^{2}-\left(\frac{1-\sqrt{f^{s t}}}{2}\right)^{2}\right)
\end{aligned}
$$

The unsteady TE separation affects the moment through the travelling of the pressure center due to separation. However as for the drag, the present model binds the unsteady moment to variations about the static moment curve provided as input. For the DTEG contribution to the dynamic moment $\left(C_{M, D T E G}\right)$ please refer to Gaunaa [4]. As for the drag, the fact of using the separation point to scale the effect of the DTEG contribution to the moment is assumed valid for the two extreme cases (fully attached flow $=$ higher order terms of the Gaunaa DTEG model is included [4] and for fully separated flow where the suggested model becomes the B-L model).

$$
C_{M}^{d y n}=C_{M}^{s t}\left(\alpha_{E, D T E G}\right)+\Delta C_{M}^{f^{d y n}}+C_{M, D T E G} \cdot f^{d y n}-\pi b \frac{\dot{\omega}}{2 \bar{U}}
$$

Please refer to the report by Hansen et al. [7] for details on the term $\Delta C_{M}^{f, d y n}$.

\section{Result}

Figure 3 illustrates that the lift for suggested dynamic stall model operates in agreement with the measurements performed in the Velux wind tunnel. For AOA at 4.6 degrees there is a good agreement between measurements, this model and the original Gaunaa model [4] with the exception that for the highest reduced frequency the measurements suggest using a slightly more open loop which may be due to viscous effects not part of the model. For AOA at 18.5 degree in deep stall the DTEG flapping motion creates loops which are well captured by the model, notice how the loop slope is becoming steeper for increased reduced frequency this is also seen in the measurements. The suggested model should be extended to include measurements or CFD calculations of drag and moment coefficients in a similar manner to the way the lift coefficient is adjusted according to static measurements. Figure 4 combines the pitching and DTEG motion in counter phase, which means the DTEG, compensates the pitching motion of the profile. The results shown are given by the suggested model using the DTEG measurements of static lift, drag and moment coefficients on a B1-18 profile as input. This figure clearly illustrates the aerodynamic complexity of combining not only the pitching motion of a profile but also adding a dynamic DTEG deflection motion. Figure 4 suggest that with the chosen pitching and DTEG deflection amplitudes in counter phase the $C_{M}$ loop slope at $A O A=4^{0}$ can be removed and the $C_{L}$ slope from pure pitching loop can be halved. It should be noted that the dynamic contribution to drag and moment from actuation the DTEG scales with the dynamic separation coefficient. This scaling causes the effect of using a DTEG to be zero in deep stall with regard to drag and moment; a better approach would be to extend the model to include the DTEG measurements for deep stall scaling of drag and moment as done for the lift.

\section{Conclusion}

A dynamic stall model has been developed which predicts the unsteady aerodynamic forces and moments on an airfoil section undergoing arbitrary motion in heave, lead-lag, pitch, trailing edge flapping. The DTEG deflection angles are limited to plus and minus 5 degrees. For zero DTEG deflections the model becomes equivalent to the original implementation of the B-L model by Hansen et al. [7]. When actuating the DTEG the model becomes equal to the Gaunaa model [4] in the attached flow region excluding some higher order terms which is part of the original Gaunaa model. For the separated flow region the model becomes a crossover between the two models when using the DTEG. The dynamic lift in stalled and attached region show good agreement with the measurements performed in the Velux tunnel. The model should be extended to scale the DTEG contribution to drag 
and moment in deep stall in a similar fashion to how the lift is scaled instead of using the simple dynamic separation point scaling.

\section{References}

[1] Basualdo, S., Load alleviation on wind turbine blades using variable airfoil geometry, Wind Engineering, vol. 29, no. 2, 2005

[2] Troldborg, N., Computational study of the Risø-B1-18 airfoil with a hinged flap providing variable trailing edge geometry, Wind Engineering, vol. 29, no. 2, 2005

[3] Buhl, T.; Gaunaa, M.; Bak, C.; Potential Load Reduction Using Airfoils with Variable Trailing Edge Geometry; Journal of Solar Energy Engineering; November 2005, Vol. 127, p. 503-516

[4] Gaunaa, M., "Unsteady 2D Potential-flow Forces on a Thin Variable Geometry Airfoil Undergoing Arbitrary Motion”, Risø-R-1478, Risø, Roskilde, Denmark, June 2004

[5] Andersen, P.B.; Gaunaa, M.; Bak, C.; Buhl, T., Load alleviation on wind turbine blades using variable airfoil geometry. In: Proceedings (online). 2006 European Wind Energy Conference and Exhibition, Athens (GR), 27 Feb -2 Mar 2006. (Wind Energy Ass., Brussels, 2006) 8 p

[6] Abdallah, I.; Advanced Load Alleviation for Wind Turbines using Adaptive Trailing Edge Geometry: Sensoring Techniques. M.Sc Thesis Project; July 13, 2006, Technical University of Denmark, Department of Mechanical Engineering, Section of Fluid Mechanics

[7] Hansen, M.H., Gaunaa, M., Madsen, H.Aa. "A Beddoes-Leishman type dynamic stall model in state-space and indicial formulations", Risø-R-1354, Risø, Roskilde, Denmark, June 2004.

[8] Bak, C., Gaunaa, M., Andersen P.B., Buhl T., Hansen P., Clemmensen K., Moeller R., "Wind Tunnel Test on Wind Turbine Airfoil with Adaptive Trailing Edge Geometry", Paper for conference AAIA-2007-1016, Reno, USA, Jan 2007

[9] von Karman, Th. \& Sears, W.R., "Airfoil Theory for Non-Uniform Motion.”, Journal of the Aerodynamical Science. 5(10) 1938. p.379-390

[10] Thwaites, B.E. "Incompressible Aerodynamics", Cambridge University Press, 1961

[11] Jones,R.T.,"The Unsteady lift of a Wing of finite Aspect-ratio",Tech.Rep.681, NACA rep, 1940

[12] Theodorsens, T., "General Theory of Aerodynamic Instability and The Mechanism of Flutter," NACA Report 496, 1935, pp. 413-433

[13] Friedmann, P.P., "Rotor-Wing Aeroelasticity: Current Status and Future Trends", AIAA Journal Vol. 42, No. 10, October 2004. 

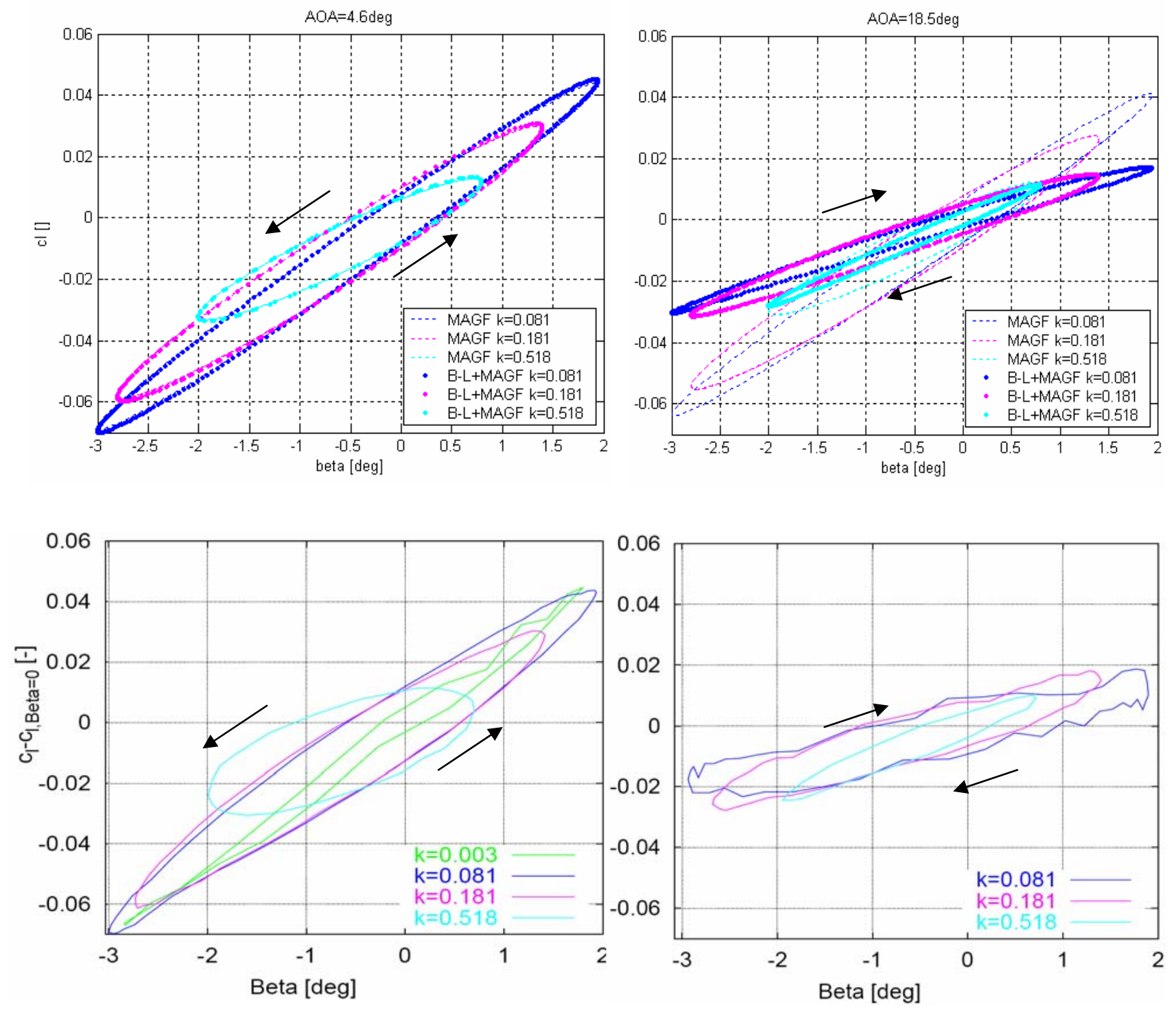

Figure $3, \Delta C_{L}$ loops as function of $\beta$ for AOA at $4.6^{0}$ (top left) and $18.5^{0}$ (top right) using $A_{i}, b_{i}$ parameters for a Risø-B1-18 profile and shifted so $\Delta C_{L}=0$ for $\beta=0^{0}$. (Bottom left) shows the measured $\Delta \mathrm{C}_{\mathrm{L}}$ loops from Velux described by Bak et al. [8] for $\mathrm{AOA}=4.6^{\circ}$ and (bottom right) $\mathrm{AOA}=19^{0}$. The (top left) and (top right) results for model presented in this work (C-L+MAGF) are based on the measured static $\Delta \mathrm{C}_{\mathrm{L}}$ curves. The DTEG deflection $\beta$ ranges from $-3^{0}$ to $1.97^{0}$ for reduced frequency $\mathrm{k}=\omega \mathrm{c} /(2 \mathrm{Uo})=0.081$, for $\beta=-2.8^{0}$ to $1.3^{0}$ the $\mathrm{k}=\omega \mathrm{c} /(2 \mathrm{Uo})=0.181$ and finally for $\beta=-2^{0}$ to $0.76^{0}$ the $\mathrm{k}=\omega \mathrm{c} /(2 \mathrm{Uo})=0.518$. Arrows indicate the orientation of the loops in time. 

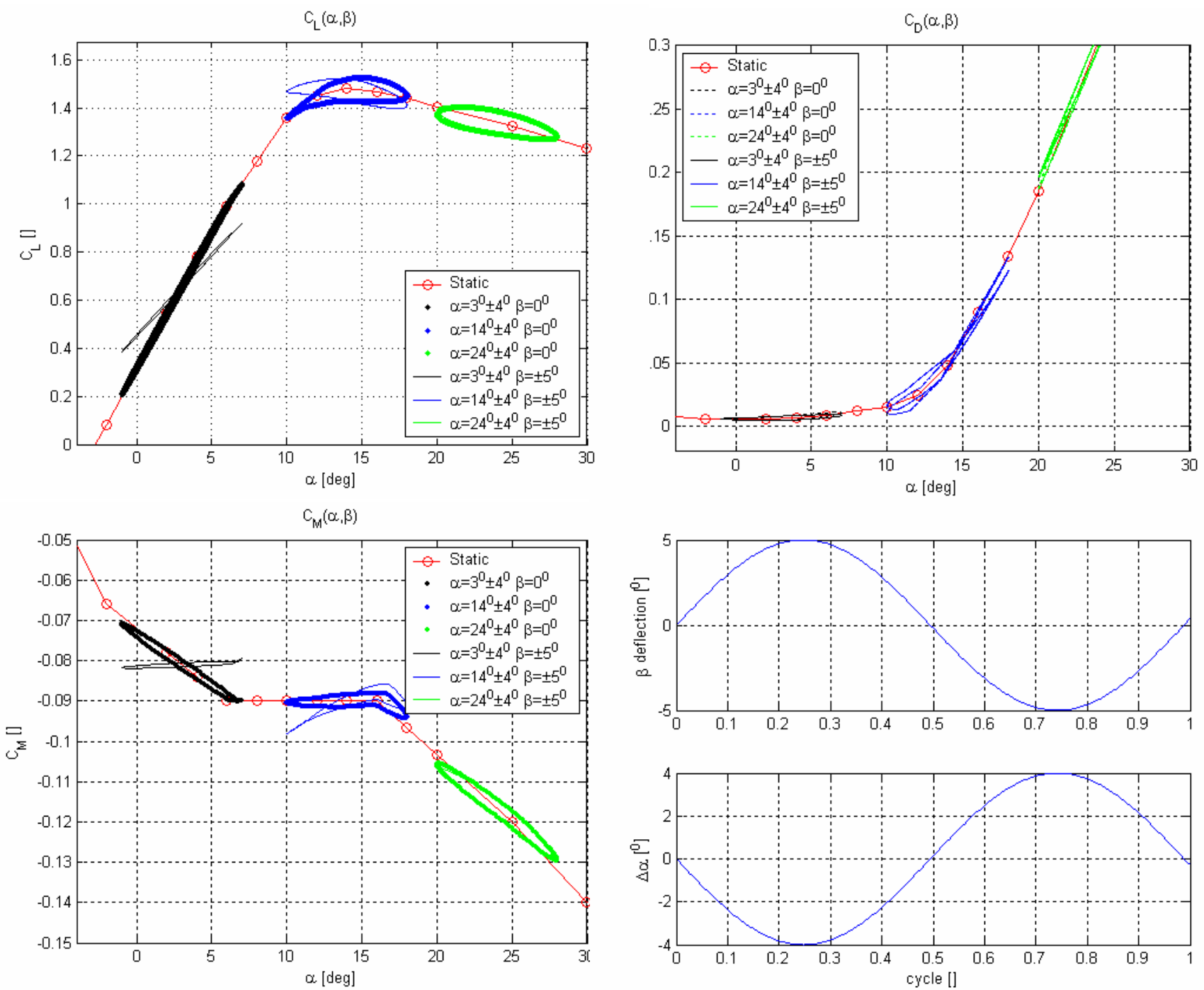

Figure 4. Response of $C_{L}$ (upper left), $C_{D}$ (upper right) and $C_{M}$ (lower left) to oscillatory pitching motion without the use of DTEG deflection and with use of DTEG deflection. The results are given by the suggested model using the DTEG measurements of static lift, drag and moment coefficients on a B1-18 profile as input. Reduced frequency is $\mathrm{k}=\omega \mathrm{c} /(2 \mathrm{Uo})=0.1 . \Delta \alpha=4^{\circ} \Delta \beta=5^{\circ}$ 